\title{
Push-pull plus: reconsidering the drivers of migration
}

\author{
Nicholas Van Hear
}

Centre on Migration, Policy and Society, (COMPAS), University of Oxford 58 Banbury Road, Oxford, OX2 6QS

nicholas.vanhear@compas.ox.ac.uk

Oliver Bakewell

Global Development Institute, University of Manchester, Manchester, UK oliver.bakewell@manchester.ac.uk

Katy Long

Independent consultant

San Francisco and Oxford

katy.long@gmail.com 


\section{Push-pull plus: reconsidering the drivers of migration}

Drivers can be understood as forces leading to the inception of migration and the perpetuation of movement. This article considers key drivers of migration and explores different ways that they may be configured. We modify existing explanations of migration to generate a framework which we call push-pull plus. To understand migration flows better, analysts could usefully distinguish between predisposing, proximate, precipitating and mediating drivers. Combinations of such drivers shape the conditions, circumstances and environment within which people choose to move or stay put, or have that decision thrust upon them. In any one migration flow, several driver complexes may interconnect to shape the eventual direction and nature of movement. The challenge is to establish when and why some drivers are more important than others, which combinations are more potent than others, and which are more susceptible to change through external intervention. Drawing on Afghan and Somali movements featuring 'mixed migration', the article concludes that proximate and mediating drivers, rather than those in the structural and precipitating spheres, appear to offer greater potential for intervention. To be effective, though, migration policy should be understood not simply as a stand-alone lever, but within the wider political economy.

Keywords: drivers of migration; push-pull; migration theory; mixed migration; migration policy; Afghans; Somalis

\section{Introduction}

Why do people migrate? And how do they choose where to go? These questions are not only of interest to social scientists, but also to policymakers seeking to direct, increase or decrease immigration and emigration (Carling and Collins 2017 this issue). This article builds on existing frameworks for understanding migration - notably, the 'pushpull' model - to develop a more nuanced account of the fluid and shifting driver complexes that shape migration. We present an analytical framework that teases apart 
the different mechanisms through which any particular factor might serve to influence people’s migration decisions and migration processes. We call these factors, often functioning in combination, drivers. We observe how they operate differently across contexts, interacting with each other to shape the ever-changing structural space in which people make their mobility decisions.

Over the last two decades, scholarly consensus has established that structural forces lead to both the inception of migration and the perpetuation of movement (Massey et al. 1998). Taken together, these structural forces can be understood as the drivers of migration - the factors that get migration going and keep it going once begun. This article sets out to identify migration's key drivers and explore how they may be configured. It points out ways to assess their different significance, or weight, and to investigate their relationship with development.

We see drivers as structural elements that enable and constrain the exercise of agency by social actors. While some may describe aspirations and desires as driving people’s migrations (Benson and O’Reilly 2009), we propose the term driver be reserved for the more external material forces that influence mobility, such as political climate or the existence of transport infrastructure. Though drawing attention to the structural quality of drivers, we are not using the term in a determinist sense, as if they are factors that propel people on set paths. Instead, we argue that drivers work by making certain decisions, routes or destinations more likely and bringing them within the orbit of people's capabilities.

While acknowledging the critiques of analysts who view push-pull models as too simplistic and determinist (Skeldon 1990; de Haas 2011), we still find some merit in the simple notion of push-pull, with its intuitive and empirically grounded idea that structural forces shape migration processes. By offering a more nuanced understanding 
of how these forces work, however, this article provides a more solid conceptual base for analysing them. In short, we are making a case for what might be called 'push-pull plus'. Our objective is to offer a conceptual framework as a starting point for analysing complex migration flows that continually confound expectations.

To achieve this, we start the next section with a brief discussion of the literature on the drivers of migration and how they are incorporated in different theoretical models. The subsequent section sets out our framework for analysing the drivers and introduces the concept of driver complexes, whereby drivers interact and shape migration patterns. We then ground the discussion by applying this framework to complex migration streams - those of Afghans and Somalis - that feature both 'forced' and 'voluntary' migration. Our decision to focus on two developing and conflict-ridden regions as our empirical examples reflects our own research interests. ${ }^{1}$ However, it also addresses policymakers’ specific concern with shaping, managing and controlling migration from these regions and the fact that structural factors driving migration from them are often plainly in evidence. Nevertheless, our framework has global application: for instance, it could as easily be used to examine the structural factors shaping migration between high-income countries as those in the 'global south' that we highlight.

\section{Push-Pull Redux}

Explaining migration's inception and perpetuation has conventionally focussed on disparities in conditions between place of origin and place of destination. Push-pull models in some of the classical literature suggested that migrants were pushed by low incomes in their countries or regions and pulled by better prospects in more affluent areas (Lee 1966; Harris and Todaro 1970). Critics of this approach argued that longstanding inequities deriving from centuries of poor countries being exploited by 
rich ones drove migration, which was perpetuated by the structures of labour markets in richer countries (Castles and Kosack 1973; Sassen 1988). Others have suggested that push-pull models amount to little more than lists of factors 'which lack a framework to bring them together in an explanatory system’ (Skeldon 1990: 125). The static character of such models is another shortcoming. In presenting migration as a single action rather than a process, push-pull in its original incarnation failed to account for changing motivations, altered circumstances or modified decisions en route (de Haas 2011).

Other explanations for migration's inception and perpetuation have been sought at the micro-level, such as in household decision-making, or the meso-level, such as in social networks. Some have seen migration as a household strategy motivated by the need to spread risk, rather than an individual matter (Stark 1991). Others have underlined the importance of chains, networks and culture in keeping migration going once it is established by pioneers (Boyd 1989). Such approaches provide valuable nuance and highlight the relevance of individual and group agency. However, they risk understating the extent to which migration is also shaped by other structural dimensions.

Poverty was at first held as a key structural driver of out-migration. However, since the early 1990s, there has been recognition that the poorest rarely can migrate since resources are needed to do so, especially for international migration (Tapinos 1990). It is therefore typically not the 'poorest of the poor' who migrate (UNDP 2009). While there may be a strong relationship between migration, poverty and its alleviation, poverty in itself may not be a driver of migration (Van Hear and Sørensen 2003). This acknowledgement has led to much debate about the relationship between migration and development, in particular whether development can reduce the pressures that drive migration or can in fact stimulate more migration by giving people the resources to 
move (for reviews of the debate on migration and development, see de Haan 1999; Spaan et al. 2005; Skeldon 2008; Faist 2008; de Haas 2010). Others have argued that analysis should focus on inequality and uneven development, rather than poverty, as the major driver of South-North migration (e.g. Castles 2004).

While our focus is on the structural forces shaping people's migration behaviour, we do not come from a structuralist position that only seeks explanation in forces that operate beyond the reach of the individual migrant or other social actors. Instead, we understand decisions to migrate - or to not migrate - and the emergence of wider patterns of migration as being the outcome of an interplay between these social structures and agency.

Notions of structure and agency are the subject of lively on-going debates in migration studies (Bailey 2001, Bakewell 2010, Goss and Lindquist 1995, King 2012, Morawska 2001). The term agency is often simply used to refer to an individual's freedom of choice, as it is exercised in the face of macro-level social structures that serve to both enable and constrain their action. However, this tends to reduce the discussion to one level of analysis: the micro versus the macro - say, the plucky individual working with or against the larger impersonal forces they encounter. This individualistic account of agency tends to obscure how individuals' ability to act depends on the social milieu in which their action is performed. The 19th century migration of Irish smallholders to the US during the Great Famine, for instance, demonstrated not just the exercise of free choice, but also the structural framing of US migration policy, UK agrarian policy and transatlantic shipping routes, among other drivers.

Thus, we take agency to be not only about individuals’ power to act in and of themselves, but also to have a more relational quality. As Sewell (1992: 20) puts it: 'To 
be an agent means to be capable of exerting some degrees of control over the social relations in which one is enmeshed, which in turn implies the ability to transform those social relations to some degree.' In this sense, agency is concerned with people’s capabilities to take their aspirations and transform them into changed positions in the social - and geographical - world.

Yet, agency is still enabled and constrained by structural conditions that lie beyond the scope of any one individual's social relations. This is not to say that structural conditions simply arise from the outside world since they may encompass an individual's attributes given or fixed at the time of the decision to act. Such attributes include gender, race, age and level of education. Moreover, the repertoire of possible and, indeed, desirable behaviours is structured by choices and consequences of past decisions and behaviour, which may play a critical role in enabling and constraining action. However, we do not think of these as drivers, but rather as internal or ascribed characteristics. For analytical purposes in this article, the term drivers is reserved to describe the array of factors that may make up the external structural elements shaping the decision space for those considering migration. Drivers thus shape the broader context within which aspirations and desires to migrate are formed and in which people make their migration decisions - whether to move or not. To be sure, those decisions and actions can ultimately help shape structures - or put another way, agency and structure play into one another -- but our purpose in this article is to separate for analytical purposes the structural character of drivers from migrant agency, aspirations and desires.

In developing this notion of drivers, our concern is to achieve a more nuanced understanding of how such aspirations and desires arise, how individuals make their decisions, and how broader migration patterns emerge, which then help create structural 
conditions for subsequent migration (Bakewell et al. 2016). As we show in this article, drivers comprise elements in the chain of causation - from root causes to immediate triggers - that compel people to finally set off on their journeys or alternatively to stay put. We therefore echo the distinction by Carling and Talleraas (2016: 6) between root causes as 'the social and political conditions that induce departures' and drivers as 'a more inclusive term that also encompasses the mechanisms that eventually produce migration outcomes'. We acknowledge that our definition of drivers is broad, but by laying out the mechanisms by which different drivers actually influence migration processes, we present them as the more comprehensive 21st-century descendants of their push-pull forebears.

\section{Identifying drivers}

This section looks at ways in which drivers may be identified and then specifies a framework for understanding them, both singly and in interlocking complexes. Crucial questions include how, where and when drivers operate to shape migration. As we elaborate, they may operate at different scales and levels of social structure. They may operate in different locations, at places of origin, transit and destination. They may influence migration over different timeframes - as Massey et al. (1998: 42) observe, 'the conditions that initiate international movement may be quite different from those that perpetuate it across time and space.' Accounts of migration's inception and perpetuation need to address these different dimensions, which we pick up later in the article.

Mindful of our discussion so far, we explore the relationship between drivers of migration that may be deeply embedded in the economic, social, political, cultural and environmental context and more immediate drivers that intrude on people's lives to impel movement. There has been a longstanding debate on such dynamics. Drawing on 
the work of Giddens, Richmond (1994) described factors that enable and constrain migration of proactive and reactive kinds, identifying what he called predisposing factors, structural constraints, precipitating events and enabling circumstances. In a modification of this approach, Van Hear (1998) suggested that predisposing, proximate, precipitating and intervening factors shaped what he termed 'migration orders'.

We take these ideas as a point of departure for developing our conceptual framework. We aim to emphasise how the role of a particular factor - whether located in economics, politics, security, geography or another sphere - may change over time or affect individuals and communities differently. This means that rather than seeing particular factors as having fixed roles, we view them as having a range of functions which drive migration processes. Put simply, we see factors as conditions that may shape migration and drivers as activated factors. We now elaborate what we see as predisposing, proximate, precipitating and mediating drivers.

Predisposing drivers contribute to the creation of a context in which migration is more likely. Such drivers become manifest in structural disparities between migrants' place of origin and place of destination, both being shaped by the global macro-political economy. These drivers may include the unequal outcomes of broad processes such as globalisation, environmental change, urbanisation and demographic transformation. Economic disparities between territories of origin and destination comprise differences in earnings, livelihoods and living standards shaped by the unfolding global political economy and its inequities. Political disparities are affected by the relative prevalence of conflict, persecution and other dimensions of human rights and human security, often associated with nation-building, disintegration or reconstitution in origin regions. Environmental disparities between sending and receiving territories include the presence or absence of resources, the relative fertility of the soil, water availability and 
the extent of forest cover. Geographical factors - not least, proximity to borders and/or a desired destination - may also act as predisposing drivers. Some of these components are quantifiable, such as differentials concerning income per capita, per capita expenditure on health and education, number of health workers per capita and relative level of school enrolments.

Proximate drivers have a more direct bearing on migration and are derived from the aforementioned deep-seated structural features. In countries and regions of origin, they include manifestations such as economic or business cycle downturns; a turn for the worse in the security or human rights environments generated by repression or a power struggle; large-scale development projects that involve displacement and marked environmental degeneration, including the effects of climate change. In places of destination, they include manifestations such as economic upturn or wider societal improvement, yielding new employment opportunities, business development, the pursuit of trade and new educational opportunities. Some predisposing drivers may also act as proximate drivers. For example, any of the economic, political and environmental disparities - or taken collectively, disparities in human security - may become proximate drivers as they become more acute.

Precipitating drivers actually trigger departure, as individuals and households take decisions to move or stay put. Precipitating factors are usually tied to an identifiable event or events. They may occur in the economic sphere, such as a financial crisis, a drastic rise in unemployment, a factory closure, a collapse in farm prices, the imposition of punitive taxation, or the disintegration of health, education or other welfare services. Or they may be located in the political/security sphere, involving persecution, disputed citizenship, the escalation of conflict, massacre, outbreak of war and invasion. Natural or environmental disasters such as earthquakes, hurricanes and 
floods may also precipitate the movements of populations. On the pull side, the opening up of employment opportunities, a liberalised environment for small businesses and the temporary relaxation of immigration controls and family reunion regulations are the kind of developments that may precipitate migration. Again, a strong relationship exists with proximate drivers, but unlike the previous two sets of drivers, precipitating drivers are often observable, identifiable events or developments. Although they usually occur in places of origin, they may come about in places of destination too.

Mediating drivers enable, facilitate, constrain, accelerate or consolidate migration, and may diminish migration too. Those that facilitate migration include the presence and quality of transport, communications, information and resources needed for the journey and transit period. Drivers that constrain migration include the absence of such infrastructure and the lack of information and resources needed to move. The migration regime, which embraces the efforts of national and international organisations to manage migration, has a mediating function, although there is debate about just how much influence the panoply of policies governing emigration, immigration and border crossing has (Castles 2004, Czaika and de Haas 2013). Policies and practices in other spheres - such as trade, education, agriculture, rural development, welfare and housing - are also likely to be drivers enabling or constraining migration. Migrant networks encompassing source, transit and destination countries, as well as the burgeoning smuggling industry, may also play an important mediating role (Bakewell et al. 2016). A related factor is the 'culture of migration' that can emerge among people and communities who become habituated to mobility (Cohen and Jónsson 2011). This constellation of mediating drivers has usefully been conceived of as 'migration infrastructure' (Xiang and Lindquist 2014), which has major bearing on the production of 'would-be migrants' - those who aspire to migrate but do not necessarily do so 
(Xiang 2014; Carling 2014). Such mediating drivers may be rather diffuse compared to those performing other functions that we have so far discussed. Still, through enabling and constraining movement (both in aspiration and actuality), they can play a decisive role in determining migration's volumes, forms and directions. If the decision to move is determined by precipitating drivers, the desire to move, the decisions about how and when to leave, which household members should go, and where to, are shaped by these mediating drivers.

Together, the various drivers of migration create the structural conditions within which people make decisions about whether to move or stay put. To reiterate, a structural account cannot alone explain migration. Rather, the particular manifestations of migration are shaped by decisions and actions of the people and communities affected: how they exercise their agency to 'process social experience and to devise ways of coping with life, even under the most extreme forms of coercion' (Long 2001: 16). The extent to which they exert agency reflects their individual and collective capabilities (Sen 1999) and how much room for manoeuvre there is to exercise them in a specific encounter (Long 2001). Such capabilities are shaped by people’s gender, generation, class and ethnicity, among other social cleavages, all of which are crucial in moulding the aspirations and desires considered in this special issue The influence of other actors and agents, such as national and local government officials, businesses, international agencies, civil society organisations and various kinds of brokers, also needs to be worked into the analysis. As already noted, the relationship between the agency of social actors and the structural conditions in which they operate is the subject of longstanding debate (Bakewell 2010). To develop a comprehensive understanding of migration processes, we recognise the importance of acknowledging the agency of the many actors involved. For this article, however, we continue to focus on the realm of 
drivers - which we have specified as arising outside the individual or household - rather than attempt to incorporate a full account of agency.

\section{Refining the framework: dimensions of drivers}

Having established a framework incorporating different orders of drivers, we now refine our understanding of them by looking at some of their dimensions and how they may be configured in driver complexes.

We may think of a driver as emerging from or being associated with a particular domain of the social world, such as culture, geography, politics, economics, history, environment or demography. However, this gets us only so far in analysis: distinguishing between a historical, political or geographic driver does not tell us much about what the driver does or how it operates. We rather aim to tease out dimensions that characterise drivers of migration and tell us something about how they work. Besides serving their function in the migration process - be they predisposing, proximate, precipitating or mediating drivers - the dimensions comprise locality, scale, duration, selectivity and tractability.

\section{Locality}

Some drivers might be associated more strongly with the place of origin, such as demographic or environmental pressures. Others are centred on the area of destination, such as immigration policies. Still others may help shape the journey, such as geographical proximity. We also need to consider those drivers which operate transnationally or translocally, such as transnational labour markets, which might involve recruitment by agents in the place of origin to meet labour demands in destination countries. 


\section{Scale}

Two kinds of scale are considered here. Drivers operate at different spatial scales, from the local, national and regional to the global. A famine may force people living in a whole region to consider moving. By contrast, a large factory's closing or opening may change migration patterns from or to a specific town. Drivers may also operate at different social scales, from the individual, household or family to the community and wider society.

\section{Selectivity}

We may also need to explore the extent of drivers' coverage of a range of social groups. A driver may have differing impacts on various social cleavages, according to gender, generation, class, language, ethnicity, religion and so forth. For example, the establishment of a new university may draw in new migrants from a wide geographical area for education, but we would expect the migrants involved to be mainly in one age group, young adults.

\section{Duration}

Drivers operate over different time frames. For example, an acute political crisis may force people to leave their homes very quickly and take refuge elsewhere, as has been the case for many fleeing the Syrian crisis. Conversely, a chronic crisis, such as the political and economic turmoil in Zimbabwe in recent years, may result in an on-going exodus of people over a long period. It is important to note that here we are concerned with the timeframe of the driver, not of the migration. A short-term driver, such as violent conflict, may result in long-term or permanent migration and, likewise, a longterm driver may cause periodic movements back and forth rather than long-term migration. 


\section{Tractability}

Here we try to distinguish between drivers that operate on the surface of society, which may be liable to change readily with contextual shifts, and those that are more deeply embedded and intractable. For example, the driver can be seen as deeply culturally embedded if spending time away from one's community is seen as an essential step towards adulthood. Consider, for example, Mandela’s (1994: 31) claims about the South African labour migration system in the 1930s: 'In those days, working in the mines was almost as much of a rite of passage as circumcision school...' Other drivers - for example, in the economic sphere - may be less embedded and more responsive to changes in policies, such as visa requirements or employment restrictions, which make migration more expensive and less rewarding.

\section{Understanding driver complexes}

Having characterised drivers in terms of their functions and having explored some of the dimensions along which they operate, we now turn to how drivers may combine to form different complexes or configurations which shape migration processes.

As we have indicated, particular migration drivers may predispose a population to move. However, they do not work in isolation to precipitate people’s movement or to shape it once underway. Instead, migration drivers work in combination - in driver complexes - to shape the specific form and structure of population movements. As we show in our case studies, drivers can cluster to operate as more than the sum of the single drivers that constitute them. Consider this example of driver complex that can generate migration: a country of destination has growing labour market opportunities while a country of origin is in recession (both national situations reflect proximate economic drivers); the countries have a language in common (a cultural predisposing driver) and there is the presence of migration brokers and recruitment agencies 
(infrastructural mediating and precipitating drivers). Similar driver complexes may develop in very different settings. The type of cultural-economic driver complex can be associated with the Afghan and Somali migrations we analyse here as well as with the movement of highly skilled workers from the UK to the US or Australia. Moreover, in any one migration flow, several driver complexes may themselves interconnect in shaping the eventual direction and nature of a group's movement.

In the next section we consider the migration flows of Afghans to Iran and Pakistan and Somalis to southern Africa. For each case, we identify three sets of driver complexes, each operating at the place of origin, on the journey and in the destination area. We selected these two flows because they have rich, especially complex histories, connecting political insecurity, economic inequalities and cultural and social expectations. Both cases include 'forced' and 'economic' migrants, and both have been subject to direct policy interventions intended to influence their movements' direction and duration. So while neither the Afghan case nor the Somali case can be held as 'typical' migration flows, they provide highly useful illustrations of the interconnectedness of migration drivers, in terms of function and dimension.

\section{Afghan migration to Iran and Pakistan}

Driver complex one: outward migration and the political economy of conflict

Migration to Iran and Pakistan long predates the slow collapse of the Afghan state that followed the overthrow of the Afghan monarchy in 1973 (Monsutti 2006). After four decades of political insecurity, the Afghan out-migration complex has shifted. It has gone from being a fluid, continuous and multidirectional movement, motivated above all by cultural and economic interdependency in border regions (a predisposing driver), to being a set of longer-term, often irregular movements shaped (the result of proximate 
and precipitate drivers) by conflict and insecurity.

The Afghan refugee population peaked in 1990 at 6.22 million, a number which at the time represented around $40 \%$ of the entire Afghan population. Despite huge repatriation efforts - seeing 4.8 million Afghans return with international assistance following the removal of the Taliban from power in 2002 - as of May 2016, there remained around 2.6 million registered Afghan refugees, 1.5 million of whom were residing in Pakistan and 950,000 of whom were residing in Iran (UNHCR 2016). There are also 1.2 million internally displaced Afghans, a figure forecast to rise. At the same time, rising demographic pressure - the population of Afghanistan tripled from 12 million in 1990 to 35 million in 2015 - has increased competition for scarce resources and compounded the difficulties encountered in attempting to stabilise the post-conflict economy.

Contemporary Afghan out-migration to Iran and Pakistan is thus driven both by the continuing failure of the Afghan state to foster a functioning and secure society and the existence of a large Afghan diaspora. The proximate cause of such migration is not the direct impact of conflict and militarisation, but continuing poor prospects for refugee reintegration, especially in urban areas (UNODC 2010), and broader economic stress.

Continuing Afghan labour migration to Iran and Pakistan was viewed as an almost inevitable reaction to endemic state fragility and chronic economic underdevelopment from decades of conflict and state militarisation. Pre-existing labour networks and cultural familiarity with migration as an effective livelihood strategy have thus been co-opted into current outflows caused by the lack of a functioning Afghan economy. Personal lived experience of displacement in Pakistan and Iran also means that these areas and regions may often be viewed as at least as plausible a home as 
Afghanistan for many returnees who were born in exile or left as children. The political economy of conflict therefore comes to function as a proximate, precipitating and increasingly (as the driver timeframe expands) predisposing driver of Afghan outmigration.

Driver complex two: inward migration and the political economy of opportunity The inability of the Afghan state to provide security - the political economy of conflict - explains the out-migration of many of its citizens. Afghan migrants' reasons for choosing to move towards Iran and Pakistan, however, are closely tied to a political economy of opportunity. These drivers also operate across different multiple dimensions (scale, locality, timeframe) and functional levels (predisposing, proximate).

The most potent structural driver predisposing Afghans to move towards Iran and Pakistan is economic inequality. GDP per capita in the three countries shows the disparity: Afghanistan’s is \$634 US Dollars, in contrast to Pakistan’s \$1317 US Dollars and Iran’s \$5443 US Dollars (World Bank 2015). Furthermore, the Iranian and the Pakistani economies are structurally dependent on cheap migrant labour.

Additionally, certain economic activities - for example, driving a taxi in the town of Quetta, which lies in Pakistan just across the border with Afghanistan - have become the preserve of the Afghan migrant population. Specific contributions of some local skilled workers - notably, Turkmen carpet weavers in Pakistan’s Khyber Pakhtunkhwa (formerly North West Frontier Province) - have also been recognised as making a valuable economic contribution to Pakistan.

Cultural ties and geographical proximity are additional predisposing drivers influencing the choice of Iran and Pakistan as destination countries. Close cultural ties reflect economic interdependencies between the Pashtun communities that straddle the Afghan-Pakistan border. Similar ties to Iran are seen among the Tajiks (Persian- 
speaking Afghans in Herat Province) and the Hazara (a Shiite minority residing in central and northern Afghanistan). These ethnic and cultural ties are mirrored in the profiles of the Afghan communities in Iran and Pakistan (ICG 2009).

It is important to note that perception of a political economy of opportunity in Pakistan and Iran is relative to Afghans' socioeconomic status. The populations who continue traveling to Pakistan and Iran are not the poorest within Afghan society and have some access to capital. However, they should be broadly categorised as labourers rather than middle-class or elite Afghans. There is also a global Afghan diaspora, with significant resident populations in the US, Canada and the EU, often holding dual citizenship, as well as considerable numbers of elite Afghans resident in the UAE and other Gulf states (Jazayery 2002). The global diaspora magnifies the economic stratification within the regional diaspora and the ability of the wealthiest migrants to travel out towards greater opportunities in other political settings (Van Hear 2006 and 2014). Socioeconomic status can therefore be seen as a mediating driver, especially for establishing migration's volume and locality.

\section{Driver complex three: the journey}

In the past decade, international and state-driven policy responses, aimed at both facilitating refugee return and regulating Afghan migration, have made Afghan migrants’ journeys to Iran and Pakistan overwhelmingly irregular, clandestine and risky.

Both the Iranian and the Pakistani governments' insistence on linking refugee repatriation with permanent removal of Afghan populations from their territory has ignored the deep structural drivers of migration we have so far outlined. The situation has been exacerbated by increased restrictions on labour market access by Afghans (even those from registered refugee populations). The result is that irregular flows have 
come to replace earlier refugee movements. In Iran and Pakistan, the governments stay fixated on the idea of return, and have periodically set deadlines for the return of all Afghan refugees. At the time of writing (December 2016), Pakistan's government was saying that that all registered Afghans would be expected to leave by March 2017, prompting a new surge in returns to Afghanistan (Parvaz 2016).

Irregular migration is also mediated by deep local drivers, culture and geography. Kin networks and tribal links facilitate the development of informal migrant networks and smuggling routes. The close proximity of cities such as Kabul and Peshawar makes planning journeys to Pakistan relatively simple. The route between Kabul and the Pakistani Torkham border, thanks to a new road built by the US, now takes just three and a half hours.

Some strategies to encourage refugee return have acknowledged the connection between labour migration and repatriation - for example, Iran's promotion of a labourpermit scheme, whereby registered Afghan refugees could qualify for a permit granting them rights to reside and work (renewable for up to three years) if they first took their families 'home’ to Afghanistan (UNHCR 2008: 20). However, many observers see the Iranian government's actions as a covert means of boosting return rates by increasing bureaucratic obstacles to legal residency and opportunities for deportation.

\section{The corridor from south-central Somalia to southern Africa}

Driver complex one: outward migration and the political economy of conflict

Out-migration from Somalia is a result of human insecurity culminating from endemic conflict and consequent inability to access secure livelihoods. This on-going conflict arises from the interaction of different political, economic and cultural factors within Somalia. A close relationship exists between the proximate drivers of Somali out- 
migration - conflict and insecurity - and the deeper predisposing impact of structural economic underdevelopment. Both local drivers have, in turn, been exacerbated by regional environmental stress, with the large wave of out-migration in 2011 and 2012 precipitated by the intersection of drought and insecurity causing famine.

South-central Somalia is the region to have suffered most from the effects of conflict and insecurity in recent years. Concentrating on the drivers operating here, we see that the majority of those on the move between 2009 and 2012 were compelled to flee by armed conflict between the Transitional Federal Government of Somalia (TFG) and Al-Shabaab, Hizbul Islam and other Islamist groups. We therefore observe that it is the absence of basic security which provokes flight. However, it should be noted that it may be a lull in fighting which actually, finally, triggers a population's movement, even though the migration's proximate causes are violence and insecurity (see Lindley 2011).

Somalis are often portrayed as nomadic wanderers, culturally predisposed to migrate, as perceived in the existence of a global Somali diaspora with deep historic roots. However, some of the south-central Somalia clans most affected by recent conflict and drought lack a history of seafaring ‘adventure’ and do not make up a significant proportion of the Somali diaspora. Groups including the Digil, the Rahanweyn and the non-Somali Juba and Wabi Shebelle Valley populations are not traditionally nomadic, but rather are sedentary agriculturists who since 1991, have found themselves especially vulnerable to attack by armed militia (Prunier 1996: 51). Nevertheless, for other south-central groups, such as the Ogaaden, close cultural affinities with Somali populations in Ethiopia and Kenya as well as a long history of cross-continental diaspora movements may have predisposed the cultural use of migration as a means of maximising opportunity. 
Importantly, the impact of the 2009-2012 conflict was heavily influenced by proximate environmental stressors. Persistent rains from March 2010 caused flooding across southern and central Somalia by June, leading to widespread destruction of property, livestock and crops. At least 6000 additional household displacements were triggered by the floods, many moving into IDP camps. UNHCR reported a rise in the number of refugees arriving in Kenya. This single event is the manifestation of deeper environmental insecurities (drought in 2005 precipitated similar out-migration).

The migration drivers of south-central Somalia’s out-migration can thus be conceptualised as a complex centring on conflict and ensuing human insecurity. In the Somali case, the lack of rule of law and basic physical security has devastating proximate economic consequences. The duration of the war and the absence of a functioning Somali state, however, means that these proximate causes of flight have, over time, become more deeply rooted predisposing drivers.

Driver complex two: inward migration and the political economy of opportunity Incoming Somali migration to the Republic of South Africa (RSA) is due to a political economy of opportunity, reflecting structural inequalities between Somalia and RSA in terms of wealth and security. Since the end of apartheid in 1994, South Africa has established a relatively stable, democratic government under a constitution which guarantees a plethora of rights and freedoms to ‘all people in our country', not just citizens or legal migrants (RSA Constitution 1996: Article 7). It is unlikely that these rights are themselves a predisposing factor explaining the choices of Somali refugees and migrants to move towards RSA, but rather it is the political economy of opportunity that they foster. Onward movement of Somali refugees from Kenya is driven not by a search to find freedom from persecution or violence, but above all by an interest in accessing the labour market and maximising economic opportunities. Importantly, 
South Africa (which does not recognise the Somali population as refugees on a prima facie basis) allows asylum seekers to work.

South Africa is the regional economic powerhouse, a middle-income country on a continent of low-income, often fragile states. It is integrated into the global capitalist economy and has excellent transport connections. These economic advantages have facilitated the growth of Somali trade links and explain the economic rationale behind Somali migration to the region. Also offering considerable business opportunities is the size of the South African internal market - RSA’s GDP per capita was \$6483 US Dollars in 2014 (to compare, it was \$1358 US Dollars in Kenya, East Africa’s regional economic power). Somalia’s GDP per capita in 2014 was \$543 US Dollars (World Bank 2015).

Trade and entrepreneurship hold a high cultural value for Somali populations, thereby creating predisposing cultural drivers of migration. The extent of the Somali diaspora and its well-established trading networks, not only in RSA but more widely across Africa, in Europe and North America, help Somalis be recognised as effective and successful businesspeople. They are often seen as able to undercut local traders, adding a further proximate driver to the complex shaping in-migration from Somalia to RSA. However, Somali businesspeople have been particular targets of xenophobic attacks, arguably in part because of their success at capitalising on the economic opportunities offered in South Africa (Polzer 2010).

It is also relevant to assess how crucial RSA's structural dependence on foreign labour is in attracting Somali refugees and migrants. This predisposing driver is often cited in explaining intraregional migration from other southern African states, and it undoubtedly plays a key role in explaining RSA's relative openness to in-migration, in general. Yet, Somalis are broadly traders, shopkeepers and businesspeople, rather than 
labourers. While more research is needed to properly map Somali occupations within RSA, the overall structure of the South African economy - as a capitalist market economy governed by a democratic state - is more important in Somalis' assessment of RSA as a potential migration destination.

In sum, the political and economic freedoms afforded by post-apartheid South Africa match the cultural values and resources of Somali out-migrants. Somali culture places a higher value on trade and economic opportunity than aid-dependent subsistence. South Africa's constitutional provisions allowing asylum-seekers to work offer this possibility, which is denied to those refugees who remain in East Africa. A large diaspora presence has existed in South Africa since 1994. This facilitates economic trade networks and the perpetuation of cultural values that encourage migration to South Africa, but impede social integration, which comes in contrast to other African migration flows to RSA.

Driver complex three: the journey

A second collection of drivers combine to shape the nature of Somali journeys to southern Africa, especially the RSA. These interrelated mediating drivers can be categorised in terms of logistics, culture, economics and policy. Logistics, in this sense, can be considered the practical dimensions of planning a journey - for example, migration routes offered by smuggling networks, modes of transport available and access to food or shelter.

Given the large role of conflict and human insecurity in driving Somali outmigration, many Somalis, especially from south-central Somalia, first cross the border with Kenya to arrive as refugees at Dadaab camp. However, the Kenyan state insists on Somali refugees’ encampment, thereby heavily curtailing Somali freedom of movement and preventing refugees’ legal access to labour markets. Since the 2013 Westgate Mall 
attack in Nairobi, Kenya has hardened its stance towards Somalis and repeatedly sought to shut down Dadaab camp and return all refugees to Somalia, citing security concerns over terrorism. The government has announced plans to close Dadaab entirely by May 2017 (Al Jazeera 2016).

Somalis’ onward journeys towards southern Africa are thus heavily influenced by the intersection of predisposing cultural values and practices. While they stress entrepreneurship, utility of migration for trade and the value of business, Kenyan government policies intended to restrict such movement limit economic opportunity and encourage return.

Labelling all Somalis as 'refugees' has also influenced the operation of migration drivers. Practices have developed in which refugee camps are used as pitstops on journeys southwards, with Somalis identifying the camps as points for accessing international aid to help sustain their continued movement. Up to $80 \%$ of Somalis who arrive in RSA pass through a single refugee camp, Dzaleka, in Malawi (Long and Crisp 2010; IOM 2009). In this sense, international policy - considering all Somalis refugees and a specific understanding of what 'refugee' and 'international protection' involve combines with logistical needs to shape Somali journeys to RSA. This, in turn, creates a mediating driver complex.

Though very little is known about the mechanics of Somali smuggling, it is clear that a sizeable economy is based on people smuggling from the Horn of Africa towards southern Africa, generating around 40 million US Dollars per annum (IOM 2009). Predisposing drivers include the strength of the Somali kin and clan networks, as well as the presence of a large diaspora in Nairobi and RSA who can fund smuggling and provide information to new arrivals. 
Perhaps the most important of all driver complexes mediating the Somali journey to RSA, however, is the interaction between cultural expectations, logistical capacity and a migrant's economic class and status. It is well recognised that economic status bears a direct relation to the distance travelled by those moving (Van Hear 2006 and 2014). Those who are able to move to southern Africa are likely to have access to significant resources (or at least significant credit), not least because of the high fees demanded by the smuggling economy. Access to resources also plays a notable role in determining the mode of transport used - the 5\% of Somalis who arrived in South Africa by air are likely to be those with the greatest access to funds to pay for air tickets and ensure they hold the documents necessary to pass through airport immigration screening (IOM 2009).

\section{Conclusion}

Both the Afghan and the Somali cases discussed, and further summarised in Table 1, underline the complex interactions that drive migration. We suggest that these and other cases can be productively analysed using our driver complex framework, notably its key notion of the clustering of particular drivers into complexes which are more than the sum of their parts. In both cases, deep-rooted cultural understandings and practices of migration reflect longstanding structural economic inequalities between places of origin and places of destination. In both cases, conflict and insecurity have made out-migration more likely, adding proximate drivers to the predisposing ones. And in both cases, international policy efforts intended to mediate migration by containing it have had the consequence not of stopping migration, but rather changing it into an irregular clandestine activity.

[Insert Table 1 here] 
Table 1 provides a comparison of the two case studies. They are not intended to be exhaustive, but only to test the applicability and usefulness of our analytical framework in understanding how migration is shaped by driver complexes featuring different dimensions of locality, scale, selectivity, duration and tractability.

The case studies highlight two additional crucial points. First, in the absence of appropriate and successful mediation, proximate drivers of migration - such as conflict and environmental stress - may harden into predisposing drivers. In both the Afghan and the Somali cases, a failure to mitigate the political economies of insecurity and conflict driving out-migration over the past several decades can be read as having turned a proximate driver, conflict, into a predisposing one: endemic state dysfunction. More generally, this sedimentation or transmuting of one kind of driver into another to some degree addresses the static nature of the push-pull model that we have taken as our point of departure.

Second, in-migration - that is, the choice of destination - is heavily influenced by socio-economic status: in effect, inequality (Van Hear 2014). This can be most easily quantified as economic inequality - for instance, between Iran and Afghanistan, or RSA and Kenya/Somalia. However, it is perhaps better understood as inequality of opportunity.

All this suggests that those interested in mediating or managing migration from such regions, and others, should focus efforts on initiatives that redress the imbalances. Still, these structural features tend to be deeply embedded and to change only slowly. Indeed, donor governments, international organisations and origin countries are unlikely to be able to influence the deeply embedded structural predisposing factors that drive migration. Their capacity to influence precipitating drivers very much is also limited, since they largely comprise events that are difficult to predict. This leaves the proximate 
drivers and mediating factors as the likely spheres for the most potential to exercise influence. However, as this article has argued, it is not simply a matter of influencing particular drivers. After all, they may combine to form configurations which have aggregate effects different from the particular drivers they combine, making whole different from the sum of the parts. This underlines the now often made point that to influence migration, we need a comprehensive approach. And that includes not just migration policies, but policy levers that have a wider reach - such as those covering trade, fiscal matters, welfare and security - and account for the unintended effects of policies on migration over time (de Haas 2011).

Finally, much depends on the goals of intervention - whether the purpose is to prevent or control migration, reduce migration pressure, enable people to choose to move or not or engage with migration flows in order to reduce poverty and optimise development. Our drivers of migration framework, with its push-pull plus provenance, cannot answer all these questions alone. As noted above (especially pp6-7), a fuller account would need to take account of agency, and in particular the migration aspirations and desires which are addressed in other contributions in this volume. In considering drivers separately from these for analytical purposes, our aim in this paper is to offer 'push-pull plus' as an analytical tool to help recognise the limits on migration control and management through single-issue policy initiatives when deeprooted political and economic structural inequalities remain in place. The wider hope is that this framework enhances our understanding of the changing structural configurations in which people's aspirations and desires to move or stay put are shaped and reshaped. 


\section{Acknowledgements}

A previous version of this article was written as a working paper for the Migrating out of Poverty Research Programme Consortium based at the University of Sussex and funded by the UK Department for International Development.

\section{Notes}

1. It also reflects this article's earlier life as a working paper for the Migrating out of Poverty Research Programme Consortium, led by the University of Sussex and funded by the UK Department for International Development.

\section{References}

Al Jazeera (2016), ‘Kenya delays Dadaab refugee camp closure by six months’, 16 November 2016, [online] available at http://www.aljazeera.com/news/2016/11/kenya-delays-dadaab-refugee-campclosure-months-161116130647820.html

Bailey, A. (2001) 'Turning Transnational: Notes on the Theorisation of International Migration’, International Journal of Population Geography 7(6):413-28.

Bakewell, O. (2010) 'Some Reflections on Structure and Agency in Migration Theory', Journal of Ethnic and Migration Studies, 36(10): 1689-1708.

Bakewell, Oliver, Godfried Engbersen, Maria Lucinda Fonseca and Cindy Horst, eds. (2016) Beyond Networks: Feedback in International Migration. Basingstoke: Palgrave.

Benson, M. and O'Reilly, K. (2009) 'Migration and the search for a better way of life: a critical exploration of lifestyle migration', The Sociological Review, 57(4): 608625.

Boyd, M. (1989) 'Family and personal networks in international migration: recent developments and new agendas’, International Migration Review, 23(3): 638670.

Carling, J. (2014) 'The role of aspirations in migration', paper presented at the conference Determinants of International Migration, International Migration Institute, University of Oxford, Oxford, 23-25 September. 
Carling, Jørgen and Cathrine Talleraas (2016) 'Root Causes and Drivers of Migration: Implications for Humanitarian Efforts and Development Cooperation’ PRIO Paper. Oslo: Peace Research Institute Oslo.

Carling, Jørgen, and Francis L. Collins (this issue) 'Aspiration, desire and the drivers of migration.' Journal of Ethnic and Migration Studies. n/a (n/a):n/a.

Castles, S. (2004) 'Why migration policies fail', Ethnic and Racial Studies, 27(2): 205227.

Castles, S. and Kosack, G. (1973) Immigrant Workers and Class Structure in Western Europe. London and New York: Oxford University Press.

Cohen, R. and Jónsson, G. (2011) ‘Introduction: Connecting Culture and Migration’, in R. Cohen and G. Jónsson (eds.) Migration and Culture, Cheltenham: Edward Elgar.

Czaika, M. and De Haas, H. (2013) 'The Effectiveness of Immigration Policies', Population and Development Review, 39(3): 487-50.

de Haan, A. (1999) 'Livelihoods and poverty: The role of migration - A critical review of the migration literature', Journal Of Development Studies, 36(2): 1-47. de Haas, H. (2010) 'Migration and development: a theoretical perspective', International Migration Review, 44(1): 227-64.

de Haas, H. (2011). The Determinants of International Migration: Conceptualizing Policy, Origin and Destination Effects. Oxford: International Migration Institute, IMI Working Paper No. 32.

Faist, T (2008) 'Migrants as transnational development agents: an inquiry into the newest round of the migration-development nexus', Population, Space and Place, 14(1): 21-42.

Goss, Jon and Bruce Lindquist (1995) 'Conceptualizing International Labor Migration: A Structuration Perspective’, International Migration Review 29(2):317-51.

Harris, J. and Todaro, M. (1970) 'Migration, unemployment and development: a twosector analysis’, American Economic Review, 60(1): 126-142.

International Crisis Group (ICG) (2009) Afghanistan, What Now for refugees?, [online] October 2009, available at: www.crisisgroup.org/home/index.cfm?id=6290\\&CFID=13882722\\&CFTOKE $\mathrm{N}=11480080$

International Organization for Migration (IOM) (2009) In Pursuit of the Southern Dream: Victims of Necessity, Assessment of the Irregular Movement of Men 
from East Africa and the Horn to South Africa, [online] June 2009, available at: http://publications.iom.int/bookstore/index.php?main-page=productinfo\&productsid $=507$

Jazayery, L. (2002) 'The migration-development nexus: Afghanistan case study’, International Migration, 40(5): 231-254.

King, Russell (2012) 'Theories and Typologies of Migration: An Overview and a Primer’ Vol. 3/12. Willy Brandt Series of Working Papers in International Migration and Ethnic Relations. Malmö: Malmö Institute for Studies of Migration, Diversity and Welfare (MIM) Malmö University.

Lee, E. (1966) 'A theory of migration', Demography, 3(1): 47-57.

Lindley, A. (2011) 'Between a protracted and a crisis situation: policy responses to Somali refugees in Kenya.’ Refugee Survey Quarterly, 30 (4): 14-49.

Long, K. and Crisp, J. (2010) A Long and Winding Road: Mixed Migratory Movements to Southern Africa from the East, Horn and Great Lakes Region of Africa , Background paper for Regional Conference on Refugee Protection and International Migration, Tanzania, 6-7 September 2010.

Long, N. (2001) Development Sociology: Actor Perspectives. London: Routledge. Mandela, N. (1994) Long Walk to Freedom. London: Abacus.

Massey, D. et al. (1998) Worlds in Motion: Understanding International Migration at the End of the Millennium. Oxford: Clarendon Press.

Monsutti, A. (2006) Afghan Transitional Networks: Looking Beyond Repatriation, Kabul: AREU. [online] available at: www.areu.org.af/index.php?option=comdocman $\backslash \&$ Itemid $=\backslash \&$ task=doc-download $\backslash \&$ gid $=432$

Morawska, Ewa (2001) 'Structuring Migration: The Case of Polish Income-Seeking Travelers to the West.' Theory and Society 30(1):47-80.

Parvaz, D. (2016) ‘A Hard Winter: Afghan Refugees Return from Pakistan’, Al Jazeera, 24 November 2016, http://www.aljazeera.com/indepth/features/2016/11/hardwinter-afghan-refugees-return-pakistan-161123070304234.html

Polzer, T. (2010) 'Xenophobia': Violence against Foreign Nationals and other 'Outsiders' in Contemporary South Africa, [online] June 2010, available at: www.migration.org.za/report/polzer-t-2010-xenophobia-violence-againstforeign-nationals-and-other-outsiders-contemporary-

Prunier, G. (1996) 'Somalia: civil war, intervention and withdrawal', Refugee Survey Quarterly, 15(1): 35-85. 
Richmond, A. (1994) Global Apartheid: Refugees, Racism and the New World Order, New York: OUP.

Sassen, S. (1988) The Mobility of Labor and Capital: A Study in International Investment and Labor Flow, Cambridge: CUP.

Sen, A. K. (1999) Development as Freedom. Oxford: Oxford University Press.

Sewell, W.H. (1992) ‘A Theory of Structure: Duality, Agency and Transformation’, American Journal of Sociology 98(1):1-29.

Skeldon, R. (1990) Population mobility in developing countries: a reinterpretation, London: Belhaven.

Skeldon, R. (2008) 'International migration as a tool in development policy: a passing phase?', Population and Development Review, 34(1): 1-18.

Spaan, E., van Naerssen T. and Hillmann F. (2005) 'Shifts in the European discourses on migration and development', Asian and Pacific Migration Journal, 14(1-2): 35-69.

Stark, O. (1991) The Migration of Labor. Oxford: Blackwell.

Tapinos, G. P. (1990) Development Assistance Strategies and Emigration Pressure in Europe and Africa. Washington DC: Commission for the Study of International Migration and Co-operative Economic Development.

UNDP (2009) Human Development Report. Overcoming barriers: human mobility and development. New York: UNDP.

UNHCR (2016) Pakistan Factsheet, May 2016, http://reporting.unhcr.org/sites/default/files/UNHCR\%20Pakistan\%20Factsheet \%20-\%20MAY16.pdf

UNHCR (2008) Discussion Paper: 'Towards a Comprehensive Solution for Displacement From Afghanistan', [online] July 2003, available at: www.unhcr.org/refworld/docid/3f1be2224.html [accessed 6 August 2011].

United Nations Office on Drugs and Crime (UNODC) (2010) Corruption in Afghanistan: Bribery as Reported by the Victims, [online] available at: www.unodc.org/documents/data-and-analysis/Afghanistan/Afghanistancorruption-survey2010-Eng.pdf

Van Hear, N. (1998) New Diasporas: The Mass Exodus, Dispersal and Regrouping of Migrant Communities, London: UCL Press.

Van Hear, N. (2006) ““I went as far as my money would take me”: conflict, forced migration and class', in Crepeau F. et al. (eds.) Forced migration and global 
processes: a view from forced migration studies. Lanham MA:

Lexington/Rowman and Littlefield, 125-158.

Van Hear, N. and Sørensen, N. N. (2003) The Migration-Development Nexus. Geneva: International Organisation for Migration.

Van Hear, N. (2014) 'Reconsidering migration and class’, International Migration Review, 48: 100-121. Special Issue: International Migration in the $21^{\text {st }}$ Century: Advancing the Frontier of Scholarship and Knowledge.

World Bank, (2015), GDP Per Capita: Current US \$, http://data.worldbank.org/indicator/NY.GDP.PCAP.CD?page=5

Xiang Biao (2014) 'The would-be migrant: post-socialist primitive accumulation, potential transnational mobility, and the displacement of the present in Northeast China', TRaNS: Trans -Regional and -National Studies of Southeast Asia, 2, 183-199.

Xiang Biao and J. Lindquist (2014) 'Migration infrastructure', International Migration Review, 48: S122-148. 
Table 1. Comparison of Afghan and Somali case studies

\begin{tabular}{|c|c|c|}
\hline $\begin{array}{l}\text { Driver } \\
\text { complex }\end{array}$ & $\begin{array}{l}\text { Afghan Migration to Pakistan } \\
\text { and Iran }\end{array}$ & $\begin{array}{l}\text { South-central Somali migration } \\
\text { to southern Africa }\end{array}$ \\
\hline $\begin{array}{l}\text { Outward } \\
\text { migration }\end{array}$ & $\begin{array}{l}\text { Political economy of conflict } \\
\text { Migration culturally embedded as } \\
\text { livelihood strategy, earlier refugee } \\
\text { waves (predisposing) } \\
\text { Long-running conflict and } \\
\text { continuing insecurity (proximate > } \\
\text { predisposing) } \\
\text { Economic, demographic and } \\
\text { environmental stress (proximate > } \\
\text { precipitating) }\end{array}$ & $\begin{array}{l}\text { Political economy of conflict } \\
\text { Migration culturally embedded as } \\
\text { livelihood strategy (predisposing) } \\
\text { Long-running conflict and } \\
\text { continuing insecurity (proximate > } \\
\text { predisposing) } \\
\text { Economic, demographic and } \\
\text { environmental stress (proximate > } \\
\text { precipitating) }\end{array}$ \\
\hline $\begin{array}{l}\text { Inward } \\
\text { migration }\end{array}$ & $\begin{array}{l}\text { Political economy of opportunity } \\
\text { Marked income inequality (x2 } \\
\text { GDP/capita Pakistan, x9 Iran) } \\
\text { (predisposing) } \\
\text { Structural dependence on cheap } \\
\text { labour (predisposing) } \\
\text { Cultural ties (including strong } \\
\text { Afghan control of some sectors of } \\
\text { labour market) (proximate } \\
\text { >predisposing) } \\
\text { Geographic proximity } \\
\text { (precipitating) } \\
\text { Socioeconomic status (mediating) }\end{array}$ & $\begin{array}{l}\text { Political economy of opportunity } \\
\text { Marked income inequality (x3 } \\
\text { GDP/capita Kenya, x13 RSA) } \\
\text { (predisposing) } \\
\text { RSA protection of capitalist } \\
\text { market economy (predisposing > } \\
\text { proximate) } \\
\text { Cultural value of trade and } \\
\text { entrepreneurship, diaspora } \\
\text { networks (proximate > } \\
\text { predisposing) } \\
\text { Kenyan hostility and policies of } \\
\text { encampment/return } \\
\text { (proximate>precipitating) } \\
\text { Socioeconomic status (mediating) }\end{array}$ \\
\hline The journey & $\begin{array}{l}\text { Socioeconomic status (mediating) } \\
\text { Infrastructure and presence of } \\
\text { roads/taxis networks (mediating) } \\
\text { Smuggling networks (proximate > } \\
\text { predisposing) } \\
\text { Iranian and Pakistani refugee and } \\
\text { migration policy (mediating) } \\
\text { Smuggling networks (proximate > } \\
\text { predisposing) }\end{array}$ & $\begin{array}{l}\text { Socioeconomic status (mediating) } \\
\text { Kenyan hostility and policies of } \\
\text { encampment/return (mediating) } \\
\text { Diaspora presence and strength of } \\
\text { clan ties (predisposing) } \\
\text { Smuggling networks (proximate > } \\
\text { predisposing) } \\
\text { International refugee and } \\
\text { migration policy (mediating) }\end{array}$ \\
\hline
\end{tabular}

